\title{
Das grüne Leuchten
}

"Nimm den Hund mit», hatte sie gesagt. »Bitte. "Mit dieser Stimme, die noch immer den friesischen Rhythmus besass. Manchmal träumte er mit ihrer Stimme. Dann wehrte er sich dagegen, wach zu werden. Fand dann lange nicht in seinen Körper zurück. Starrte enttäuscht auf seine Hände. Aber der Hund war nirgends zu sehen. Er probierte einen albernen Namen, erschrak, probierte einen anderen, fand ihn ebenso lächerlich, machte halblaut einen dritten Versuch. Nur ein Schaf drehte sich zu ihm um. Er erinnerte sich an ein Kirchenlied, sang es leise vor sich hin, kam aber über die zweite Zeile nicht hinaus. Eine Windböe schob ihn zwei Schritte nach vorne. Eigentlich müssten seine Füsse jetzt im Wasser stehen. Ja. Es waren seine Füsse. Sie steckten in einem Paar seiner handgenähten Halbschuhe. Er trug immer Halbschuhe. Bei jedem Wetter. Auch wenn er bei Regen und Schnee mit dem Hund weggeschickt wurde. Aber hier war kein Wasser. Er stand auf einer mit Butterblumen spärlich bestickten Wiese, die langsam und dann kräftig anstieg. Er schaute nach links. Er schaute nach rechts. "Ein Deich«, murmelte er dann und schüttelte den Kopf. „So sieht ein Deich aus. Das weisst du doch." Er sagte es mit der Stimme seiner Frau. Und diese Stimme beruhigte ihn.»Und zu einem Deich gehören auch Schafe." Er nickte. Das war alles ganz normal. Deich und Schafe. Das gehörte zusammen. Aber der Deich! Wo kam der Deich plötzlich her!

Ganz vorsichtig drehte er sich um, schloss die Augen, zählte bis drei, blinzelte, lächelte dann erleichtert. Er erkannte den Gasthof ,Zum Fischmeister. Flugfische, er dachte: Flugfische, wusste aber nicht warum. Der gelbe Anstrich! Ja. Die brennende Aussenlampe, die signalisierte, dass geöffnet war. Ja doch! Der Biergarten mit den noch kahlen, wie beleidigt aussehenden Kastanienbäumen. Ja.Ja. Seit beinahe dreissig Jahren ging er jeden Donnerstag `Zum Fischmeister . Ambach. Starnberger See. Kleine Fluchten. Zunächst drehte er eine Runde mit dem Hund. Dann betrat er kurz nach vier das Lokal. Wintertags war er dann häufig der einzige Gast. Er ass und trank immer das Gleiche. Einen schwäbischen Apfelkuchen mit Sahne. Und einen Milchkaffee. Man brachte es ihm unaufgefordert. Die trauerbeflorte Stimme der Kellnerin, wenn der Kuchen aus war und er ausweichen musste. Auf Birnenkuchen. Oder auf Käsekuchen. Manchmal setzte sich Michi zu ihm und erzählte von seinen 
Paradiesen in Indien und Myanmar. Oder Bibi, die seine Hunde liebte. Und immer las er die TAZ und den FREITAG. Abonniert hatte er die Zeitungen nie.

Er drehte sich wieder um. Da war wieder dieser Deich. Hauke, durchfuhr es ihn. Eigentlich müsste hier das Ufer des Sees sein und etwas weiter rechts der Anlegesteg. Noch war keine Saison. Das stimmte. Die Schiffe fuhren noch nicht. Aber letzte Woche hatte der Steg noch an seinem Platz ausgeharrt. Letzten Donnerstag. Ganz sicher. Er täuschte sich nicht. Er war wie jede Woche im Gasthof gewesen, hatte sein Gedeck bekommen, nachher war er auf den Steg hinausgegangen, um den Sonnenuntergang zu geniessen. Heimlich hoffte er noch immer, er würde mit dem letzten Sonnenstrahl das grüne Leuchten erleben. Eric Rohmer. Ja. Ja. Das grüne Leuchten. So hiess sein Lieblingsfilm.

Das Signal eines Schiffes. Er kannte jedes Tuten der Schiffe auf dem Starnberger See. Er konnte fehlerfrei die Schiffe auseinander halten ohne hinzusehen. Die Berg. Die Seeshaupt. Die Starnberg. Aber dieser Ton war länger und hatte mehr Gewicht. Und wo war der Hund?

"Karla hat angerufen", hatte seine Frau gesagt. Kein Licht in ihren Augen. Sie hatte die Augen abgeschirmt, als sie ging. "Nach drei Jahren. "Vor ihm der dampfende Tee. Er hatte nach draussen gestarrt. Eine Rippe der Jalousie vor seinem Fenster fehlte.

Wie beschwerlich der Aufstieg war. Sein linkes Bein schleifte etwas nach. Jetzt fehlte ihm ein Stock. Aber bisher war er zu stolz gewesen, um eine `Krücke`, er dachte immer: `Krücke` zu kaufen. Er benötigte weder Krücken noch Gedächtnisstützen. Das Gras war offensichtlich nass, denn seine Hosenbeine fühlten sich feucht an. In einem Traum hatte seine Tochter ihm einen Brief geschrieben. Aber er hatte den Brief nicht lesen können. Er hatte ihre Schrift erkannt, die gleichmässigen Bögen, die seltsam nach rechts kippenden Buchstaben. Und Kommas fehlten. Die fehlten bereits in Karlas Schulaufsätzen.

Jetzt stand er oben auf dem Deich. Er atmete schwer. Seine lehmfarbene Hose verschmolz mit dem Weg, auf dem er stand. Er schaute nach links. Der Weg verlor sich in der Ferne. Er konnte Seeshaupt nicht erkennen. Die Alpen schienen nahe an den See herangerückt und hatten sich offenbar Besiedlungen verboten. Ängstlich suchten seine Augen das andere Ufer ab. Ihm schräg gegenüber müsste sich eigentlich das Schlösschen der Akademie in Tutzing erheben. Wie oft war er dort Gast gewesen. Die Gespräche in den Salons. Spazierengehen am See. Und dort hatte er auch Margit kennen 
und lieben gelernt. Einen kurzen Sommer lang. Der Pointillismus ihrer Sommersprossen. Daran erinnerte er sich. Man durfte ihr nicht zu nahe kommen, denn dann verwischte das Gesicht. Ein Meter Entfernung. Das war der ideale Abstand gewesen. Aber er war ihr stets entweder zu nahe gekommen oder blieb zu weit von ihr entfernt. Dort, wo die Akademie normalerweise stand, erhob sich jetzt ein Leuchtturm. Ein rotweiss gestreifter Leuchtturm, so einer, wie er ihn als Kind auf Borkum, war es Borkum gewesen?, bestaunt hatte.

Abrupt drehte er sich um. Da stand noch immer der Gasthof `Zum Fischmeister . Jetzt parkten zwei Autos vor dem Eingang.Vorhin war er noch alleine dort gewesen. Alles wie immer. Der leicht säuerliche Geschmack der Äpfel. Die Aprikosenmarmelade, die mit der Süsse spielte. Hatte er zum Milchkaffee eine Grappa getrunken? Seine Zunge tastete im Gaumen herum, wurde aber nicht fündig. Er glaubte einen Pilzgeschmack zu identifizieren, schüttelte aber energisch den Kopf. Er mochte keine Pilze, warum also sollte er ein Pilzgericht gegessen haben? Unsinn. "Du isst nie Pilze», sagte er mit der Stimme seiner Frau. Aber dieses Mal beruhigte ihn der Satz nicht.

Dann schob sich von rechts ein Schiff in sein Blickfeld. Kein Segelschiff. Nein. Sondern ein mächtiger Lastkahn, der Kohle geladen hatte. Milch und Kohle, dachte er, wusste aber nicht warum. Hoogtijd, las er. Ein Schiff unter holländischer Flagge? Ja. Genau. Der Kapitän sah ihn und winkte. Er winkte etwas übertrieben ausgelassen, wie er fand. Ein extrovertiertes Völkchen, diese Holländer! Jetzt schrie der Kapitän auch noch, versuchte den Motorenlärm zu überbieten, aber er verstand ihn nicht. Er winkte zurück und rief mit aller Kraft "Johan Cruijf». Und »Johan Neeskens«. Und der Name des Torhüters "Jan Jongbloed " fiel ihm auch noch ein. Offenbar hatte der Kapitän ihn verstehen können, denn er hupte ausgelassen mehrere Male.

Aber wo war sein Hund? Er wollte langsam umkehren, denn die Kälte kroch in ihm hoch. Er sehnte sich nach warmen Decken. Einem heissen Tee. Und zwei Seiten Italienisch übersetzen wollte er auch noch. "Üb er setzen", sagte seine Frau immer lächelnd, wenn er aufgeregt im Arbeitszimmer herumtigerte, weil er mit einer Formulierung unzufrieden war. Der Geruch des Radiergummis an seinen Fingern. Er würde mit ihr reden müssen. Über Karla. Und warum sie damals grusslos gegangen war. Und warum sie nicht mit ihm reden wollte. Und warum sie ihre Freunde vor ihnen versteckt hielt. Und über verkrüppelte Erinnerungen auch.

Er tastete in seiner Anzugjacke nach seinen Tabletten. Sie waren ganz feucht, hatten sich in derVerpackung bereits zum Teil aufgelöst. 
"Vergiss nicht die Tabletten einzunehmen", hatte ihm seine Frau eingeschärft. Aber wie hätte er wissen können, dass sich das Wetter so drastisch ändern würde?

Zunächst hörte er die Sirenen. Er drehte sich um, konnte aber nichts erkennen. Vor dem Lokal fehlten beide Autos, die dort vor Minuten noch geparkt hatten. Dann glaubte er, der Leuchtturm würde blinken. Er drehte sich erneut um und traute seinen Augen nicht. Ein Boot der Wasserschutzpolizei kam mit grosser Geschwindigkeit herangefahren. Wahrscheinlich wollten sie die Papiere des holländischen Frachtschiffes kontrollieren. Und hatte sich der Kapitän nicht etwas auffällig verhalten? Das Boot stoppte. Sie verlangten Auskunft. Aber er hatte doch nichts gesehen. Nur einen ausgelassen winkenden Kapitän! Und das war doch nicht verboten!

Die Männer griffen ihn und zogen ihn zu sich ins Boot. Ohne Vorwarnung. Heute verhielten sich alle sehr auffällig. War Föhn vorhergesagt worden? Er müsste seine Frau warnen. Die bekam bei Föhn immer Migräne. Und über Karla würden sie reden müssen.

"Haben Sie vielleicht meinen Hund gesehen?«, fragte er.

Und dann. Endlich.

Das grüne Leuchten. 